\title{
Effect of sodium valproate on plasma protein binding of diphenylhydantoin
}

\author{
P. N. PATSALOS AND P. T. LASCELLES \\ From the Department of Chemical Pathology, Institute of Neurology, The National Hospital, \\ Queen Square, London
}

SUMMARY In vivo and in vitro experimental data are presented in support of the hypothesis that sodium valproate displaces diphenylhydantoin (DPH) from plasma protein binding sites. This interaction could have important practical implications in the management of patients on combined therapy with these two drugs. Acute neurological features of DPH intoxication may be precipitated as a result of an increased free (pharmacologically active) fraction, which would not be detected by routine plasma DPH estimations since these reflect largely the bound fraction.

Sodium valproate (Epilim, Reckitt and Colman) was introduced into the United Kingdom in 1972. Early reports (Meinardi, 1971; Suzuki et al., 1972) suggested that it was an effective and relatively non-toxic anticonvulsant in its own right when used in the therapeutic range of 350-600 $\mu \mathrm{mol} / \mathrm{l}$. No serious interactions with other anticonvulsants have so far been reported, although accounts of its toxic features when used in combination with diphenylhydantoin (DPH) include nystagmus, dysarthia, and ataxia, similar to those of DPH itself. Jeavons and Clark (1974) have reported one patient who suffered from ataxia when on combined treatment with DPH and sodium valproate. The ataxia cleared after reduction or withdrawal of DPH without a change in the sodium valproate dose.

Chemically, sodium valproate is the sodium salt of a short chain branched fatty acid which is highly bound $(90 \%)$ to plasma protein (mainly albumin) in man at therapeutic concentrations. In view of the known effect of plasma free fatty acids in displacing drugs from protein binding sites (Tsutsumi et al., 1974), it became of interest to study the effect of sodium valproate on the plasma binding of DPH, which is itself highly bound $(80-90 \%)$ to protein. Only a small displacement of bound DPH would result in a significant increase in the free pharmacologically active fraction.

Accepted 23 December 1976

\section{Materials and methods}

In vivo plasma and brain DPH concentrations in rats after treatment with different drug combinations

Male albino Wistar rats weighing between 0.3 and $0.35 \mathrm{~kg}$ were used. All animals were allowed free access to water and a normal laboratory diet (diet 41B. H. B. Styles Ltd, London).

Two types of experiments were carried out. In 'acute' experiments, animals were treated with a single intraperitoneal injection of the drugs. A test group was injected with a mixture of DPH and sodium valproate (dissolved in commercially supplied solvent consisting of propylene glycol $40 \%$ and $10 \%$ alcohol in water, Parke Davis) at a dose of $80 \mathrm{mg} / \mathrm{kg}$ and 150 $\mathrm{mg} / \mathrm{kg}$ respectively. A second group of control animals was similarly injected but with $80 \mathrm{mg} / \mathrm{kg} \mathrm{DPH}$ only. The animals were then sacrificed at half hour intervals, up to two and a half hours. Blood and brain samples were obtained and analysed for DPH (Toseland et al., 1972) and sodium valproate (Patsalos et al., 1975) concentration.

In 'chronic' experiments, animals were treated for five consecutive days. Preliminary results showed that, in rats, a DPH dose of $60 \mathrm{mg} / \mathrm{kg}$ administered intraperitoneally twice a day gave plasma concentrations which were in the quoted therapeutic range in man. The animals were divided into three groups, and all were given a dose of DPH of $60 \mathrm{mg} / \mathrm{kg}$ intraperitoneally twice a day for three days. On the morning of the fourth day, group 1 was given $150 \mathrm{mg} / \mathrm{kg}$ of sodium valproate in addition, group 2 was given 100 $\mathrm{mg} / \mathrm{kg}$ of sulthiame in addition, while group 3 acted as 
the control with no second drug. These drug regimes were administered to the three groups of animals until the morning of the fifth day when, one hour after drug(s) administration, the animals were sacrificed. Blood and brain samples were obtained and analysed for DPH concentrations (Toseland et al., 1972).

\section{In vitro protein binding studies}

The displacement effect of sodium valproate on the protein binding of DPH was determined in vitro by an adaptation of the commonly used procedure (Klotz et al., 1946) of equilibrium dialysis. The analysis was carried out in $50 \mathrm{~mm}$ diameter cylindrical perspex cells $(10 \mathrm{~mm}$ wide and an inner compartment taking up to $1 \mathrm{ml}$ volume) divided by a semipermeable membrane (Visking). The membrane was washed for $30 \mathrm{~min}$ in $0.02 \mathrm{M}$ phosphate buffer, $\mathrm{pH} 7.4$, containing sodium chloride $(0.135 \mathrm{M}) .{ }^{14} \mathrm{C}$-diphenylhydantoin $\left({ }^{14} \mathrm{C}\right.$-DPH) was dissolved in $3 \mathrm{ml} 0.02 \mathrm{M}$ sodium hydroxide, and then made up to volume with phosphate buffer (0.02 $\mathrm{M}, \mathrm{pH}$ 7.4). Normal untreated human plasma or defatted plasma $(1.0 \mathrm{ml})$ was placed in one side of the cell, and anticonvulsant drug solutions $(1.0 \mathrm{ml})$ were introduced in the other. The concentration of ${ }^{14} \mathrm{C}-\mathrm{DPH}$ chosen was that of 80 $\mu \mathrm{mol} / \mathrm{l}$ which is below the upper limit of quoted therapeutic plasma levels in man. This ${ }^{14} \mathrm{C}$-DPH concentration was dialysed and analysed against various concentrations of sodium valproate $(0-880 \mu \mathrm{mol} / \mathrm{l})$ and ethosuximide (Parke Davis, 0-860 $\mu \mathrm{mol} / \mathrm{l}$ ).

The cells were placed on motor driven rollers assembled in a constant temperature box at $37^{\circ} \mathrm{C}$. The rollers rotated the cells for $18 \mathrm{~h}$ at which time equilibrium was reached.

A $0.1 \mathrm{ml}$ sample was taken from each compartment of the cell and diluted to $1.0 \mathrm{ml}$ with distilled water before the addition of $10 \mathrm{ml}$ NE 260 scintillation fluid (Nuclear Enterprises Ltd). Each sample was thoroughly shaken and then counted in a Packard 2450 liquid scintillation spectrophotometer. Counting efficiencies were determined by internal standardisation with ${ }^{14} \mathrm{C}$-hexadecane.

Free fatty acids were removed from human pooled plasma obtained from the blood bank by the method of Chen (1967). To $150 \mathrm{ml}$ plasma was added $7.5 \mathrm{ml}$ washed charcoal and the $\mathrm{pH}$ adjusted to 3.0 with $6 \mathrm{~N}$ HCL. This was stirred magnetically in a cold room for one hour. The charcoal was then removed by centrifugation at $2000 \mathrm{~g}$ for $15 \mathrm{~min}$ at $5^{\circ} \mathrm{C}$ and the treated plasma was passed through a millipore filter (pore size $1.2 \mu \mathrm{m}$ ) to remove any bacterial contamination. Finally, the plasma was dialysed against two litres of $0.2 \mathrm{M}$ phosphate buffer $\mathrm{pH} 7.4$ at $4^{\circ} \mathrm{C}$.

\section{Results}

The concentration of a drug found in brain is a reflection of the unbound fraction of that drug as assessed in plasma. Measurement of brain and plasma total concentration of a drug, and expression of the results in the form of a brain to plasma (B/P) concentration ratio, provides a parameter by which the free fraction of that drug can be measured indirectly.

\section{In vivo}

Figure 1a shows the B/P concentration ratios for $\mathrm{DPH}$ in two groups of animals in an 'acute' experiment over a two and a half hour period after a single intraperitoneal injection of either DPH or DPH and sodium valproate. The marked difference observed during the first hour, which also coincides with a peak
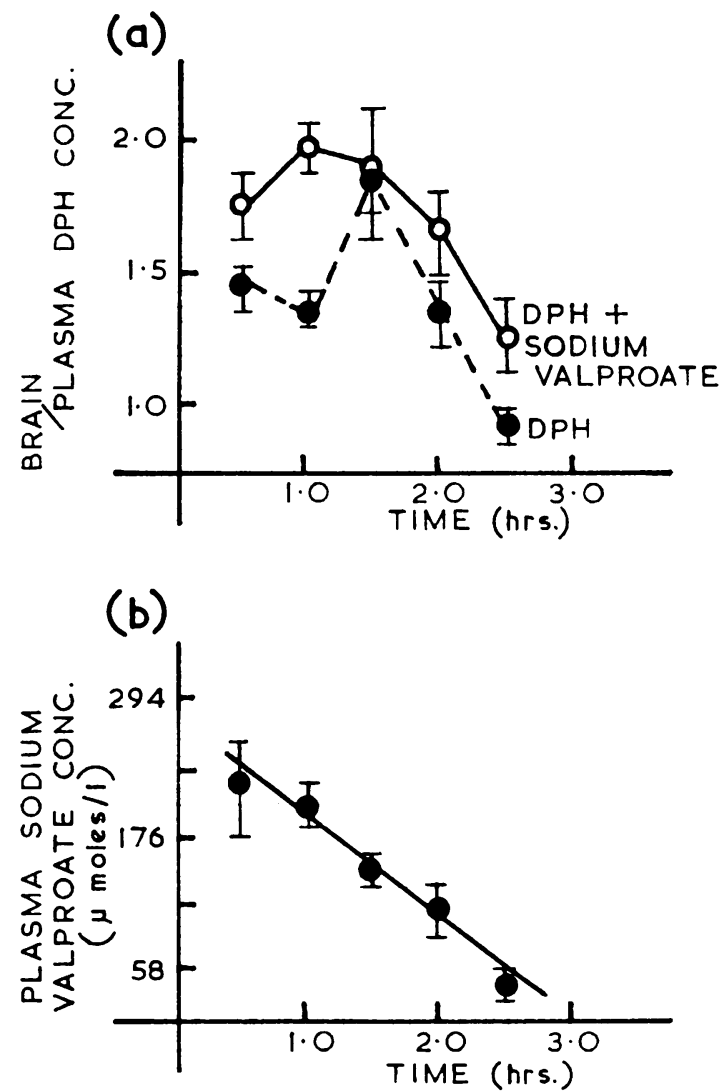

Fig. 1 (a) Brain to plasma DPH concentration ratios in two groups of animals over $a$ two and a half hour period after a single intraperitoneal injection of either $D P H$ alone or DPH + sodium valproate. (b) Plasma sodium valproate concentration over the same time period in the group of rats injected with $\mathrm{DPH}+$ sodium valproate. 
plasma sodium valproate concentration (Fig. 1b) can be explained either by the displacement of DPH from plasma protein binding sites by sodium valproate or by an effect on the blood brain barrier, but the latter is unlikely since DPH is very lipid soluble and easily penetrates that barrier. If a displacement effect is taking place it would be expected that DPH plasma concentrations would be lowered slightly and DPH brain concentrations would be raised as compared with controls which was in fact observed, as shown in Figs. 2 and 3 respectively. Table 1 a shows the B/P concentration ratio for DPH in a group of seven rats given a standard dose of DPH during a five day 'chronic' experiment. A considerable variation in plasma levels is evident; nevertheless, the plasma concentrations span the therapeutic range as assessed

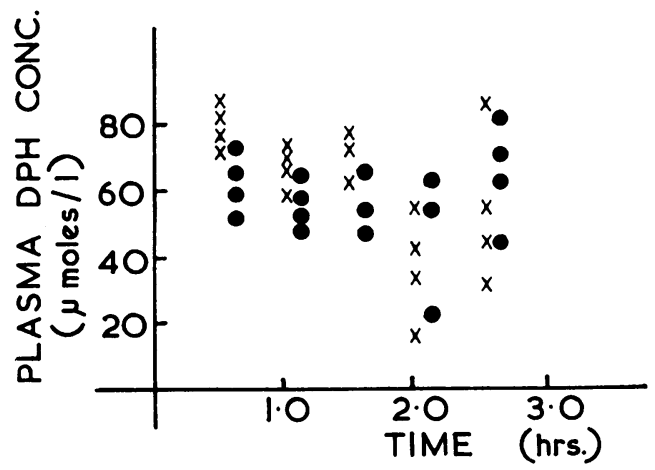

Fig. 2 Plasma DPH concentration in rats over a two and a half hour period after a single intraperitoneal injection of either $\mathrm{DPH}(\times)$ or $\mathrm{DPH}+$ sodium valproate $(\bullet)$.

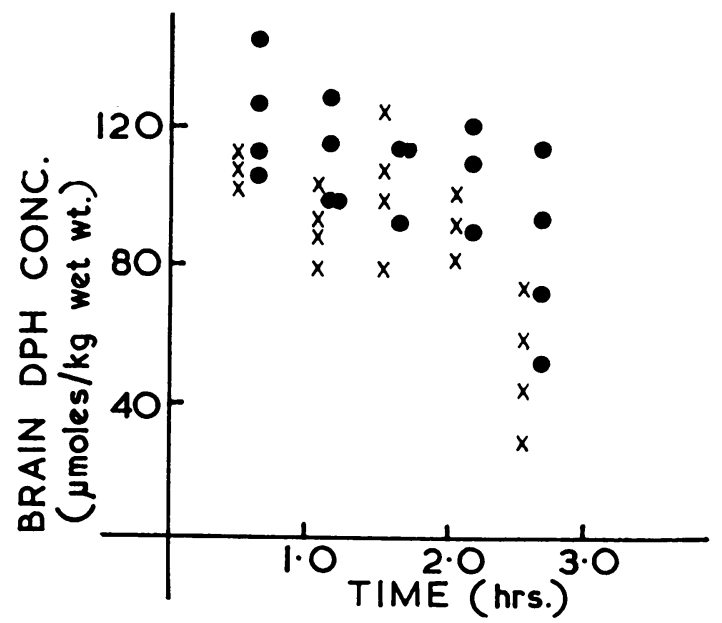

Fig. 3 Brain DPH concentration in rats over a two and a half hour period after a single intraperitoneal injection of either IPPH $(\times)$ or $D P H+$ sodium valproate $(\bullet)$.
Table 1 Brain and plasma DPH concentrations in three groups of rats given various treatments over a relatively 'chronic' five day period: (a) DPH alone; (b) DPH+ sodium valproate; (c) DPH+sulthiame

\begin{tabular}{|c|c|c|c|c|}
\hline & Rat & $\begin{array}{l}\text { Plasma } \\
\text { concentration } \\
(\mu \mathrm{mol} / \mathrm{l})\end{array}$ & $\begin{array}{l}\text { Brain } \\
\text { concentration } \\
(\mu \mathrm{mol} / \mathrm{kg} \\
\text { Het } \mathrm{n} t)\end{array}$ & $\begin{array}{l}\text { Brain/plasma } \\
\text { DPH } \\
\text { concentration } \\
\text { ratio }\end{array}$ \\
\hline \multirow[t]{8}{*}{ (a) } & 1 & 32.0 & 43.2 & 1.35 \\
\hline & 2 & 64.0 & 94.0 & 1.47 \\
\hline & 3 & 72.0 & 92.0 & 1.28 \\
\hline & 4 & 86.4 & 116.0 & 1.34 \\
\hline & 5 & 90.0 & 146.0 & 1.41 \\
\hline & 6 & 116.0 & 166.0 & 1.43 \\
\hline & 7 & 122.0 & 182.0 & 1.49 \\
\hline & & & Mean & $1.39 \pm 0.07$ \\
\hline \multirow[t]{9}{*}{ (b) } & 1 & 49.6 & 104.8 & 2.11 \\
\hline & 2 & 54.0 & 104.0 & 1.93 \\
\hline & 3 & 80.0 & 149.2 & 1.87 \\
\hline & 4 & 89.6 & 198.0 & 2.20 \\
\hline & 5 & 92.0 & 304.0 & 1.97 \\
\hline & 6 & 132.0 & 234.0 & 1.77 \\
\hline & 7 & 150.0 & 330.0 & 2.19 \\
\hline & 8 & 156.0 & 304.0 & 1.95 \\
\hline & & & Mean & $2.00 \pm 0.15$ \\
\hline \multirow[t]{6}{*}{ (c) } & 1 & 92.0 & 190.0 & 2.06 \\
\hline & 2 & 130.0 & 260.0 & 2.00 \\
\hline & 3 & 132.0 & 246.0 & 1.87 \\
\hline & 4 & 160.0 & 276.0 & 1.72 \\
\hline & 5 & 208.0 & 335.2 & 1.61 \\
\hline & & & Mean & $1.85 \pm 0.19$ \\
\hline
\end{tabular}

in man. It can be seen that the $\mathrm{B} / \mathrm{P}$ concentration ratio for DPH is remarkably constant over this range with a mean of $1.39 \pm 0.07$.

Where DPH + sodium valproate were administered together, slightly higher DPH concentrations were achieved (Table 1b), but B/P DPH concentration ratios were considerably higher with a mean of $2.0 \pm 0.15$. Furthermore, in individual animals in which the DPH plasma levels with combined drug treatment were lower than those with DPH treatment alone, the B/P DPH concentration ratio was still higher. And, in every instance the ratios were higher in animals on combined treatment than in animals on DPH treatment alone, irrespective of plasma concentration.

When sulthiame was added to the standard DPH regime, substantially higher brain and plasma concentrations of DPH were observed (Table 1c). But the B/P DPH concentration ratios were lower than when DPH and sodium valproate had been administered. This was due to the absolute levels of plasma DPH being higher which can be explained by the known inhibitory effect of sulthiame on the hydroxylation of DPH (Hansen et al., 1968; Houghton and Richens, 1974; Patsalos and Lascelles, 1976). The possibility also exists that part of this effect could be 
due to a displacement effect by sulthiame, and experiments are now in progress to test this.

\section{In vitro}

Table 2 shows the displacement effect of different concentrations of sodium valproate upon DPH binding as measured by $\%$ bound. Although a trend is apparent, statistical significance was not reached because of large standard deviations. Diphenylhydantoin binding to rat plasma protein seems to be less than that observed in human plasma. The experiment was then repeated using defatted human plasma (Table 3a), and, as expected, the absolute level of DPH binding was higher than in untreated plasma (in the presence of plasma free fatty acids). Furthermore, a trend in displacement was observed which reached statistical significance $(P<0.01)$. This is in line with observations by Jordan et al. (1975) who also carried out experiments at higher concentrations of DPH at which an even more significant trend was obtained.

Finally, Table $3 \mathrm{~b}$ shows the results of a control

Table 2 The in vitro displacement of ${ }^{14} C$-DPH from plasma protein binding sites by sodium valproate: (a) normal untreated human plasma; (b) normal untreated rat plasma. Plasma concentration of ${ }^{14} C-D P H$ is $80 \mu \mathrm{mol} / \mathrm{l}$. Results are mean $\pm S D$ of six experiments.

\begin{tabular}{lcl}
\hline & $\begin{array}{l}\text { Sodium valproate } \\
\text { concentration }(\mu \mathrm{mol} / \mathrm{l})\end{array}$ & ${ }^{11} \mathrm{C}$ - $\mathrm{DPH} \%$ bound \\
\hline (a) & 0.0 & $77.5 \pm 2.7$ \\
& 295.0 & $77.5 \pm 2.5$ \\
& 600.0 & $75.9 \pm 5.1$ \\
(b) & 880.0 & $71.9 \pm 1.9$ \\
& 0.0 & $69.3 \pm 0.8$ \\
& 295.0 & $67.5 \pm 3.8$ \\
\hline
\end{tabular}

Table 3 The in vitro displacement of ${ }^{14} C$ - DPH from plasma protein binding sites in defatted human plasma by: (a) sodium valproate; (b) ethosuximide. Plasma concentration of ${ }^{14} \mathrm{C}-\mathrm{DPH}$ is $80 \mu \mathrm{mol} / \mathrm{l}$. Results are means $\pm S D$ of six experiments.

\begin{tabular}{lcl}
\hline & $\begin{array}{l}\text { Sodium valproate } \\
\text { concentration }(\mu \mathrm{mol} / \mathrm{l})\end{array}$ & ${ }^{14} \mathrm{C}-\mathrm{DPH} \%$ bound \\
\hline (a) & 0.0 & $84.8 \pm 0.5$ \\
& 295.0 & $79.9 \pm 0.6$ \\
& 600.0 & $75.1 \pm 0.6$ \\
& 880.0 & $71.3 \pm 1.5$ \\
& & ${ }^{14} C-D P H \%$ bound \\
& Ethosuximide & \\
\hline concentration $(\mu \mathrm{mol} / \mathrm{l})$ & \\
& 0.0 & $86.5 \pm 0.4$ \\
& 290.0 & $85.7 \pm 1.1$ \\
& 570.0 & $86.7 \pm 1.4$ \\
& 860.0 & $86.0 \pm 0.8$ \\
\hline
\end{tabular}

experiment using another anticonvulsant, ethosuximide, which is weakly bound to plasma proteins (Lunde et al., 1970; Hooper et al., 1973). As expected, no displacement of DPH from its plasma protein binding sites was observed.

\section{Discussion}

The in vivo experiments described clearly demonstrate that in rats given DPH and sodium valproate, a significantly higher $\mathrm{B} / \mathrm{P}$ concentration ratio for $\mathrm{DPH}$ was achieved than in those injected with DPH alone, and that this is independent, over the range observed, of the total plasma concentration. Such an effect can be explained on the basis of displacement by sodium valproate of DPH from plasma protein binding sites and, as indicated previously, there are theoretical reasons for supposing that this is the case. Such an occurrence could explain the precipitation of neurological features of DPH toxicity in patients whose DPH plasma concentration is at the upper limit of the therapeutic range and in whom sodium valproate is added as an extra drug. This could occur without elevation of the plasma DPH concentration and, in such a situation, the monitoring of the plasma total DPH concentration would be positively misleading.

The results obtained from the in vitro equilibrium dialysis experiments using defatted human plasma, confirm by direct observation that sodium valproate slightly, but significantly, displaces DPH from plasma binding sites. The small change observed in the \% bound from 84.8 to $71.3 \%$-in the presence of 880 $\mu \mathrm{mol} /$ litre sodium valproate which is slightly above the accepted average therapeutic level in manrepresents a large increase in the DPH available pool. The $\%$ free fraction of DPH almost doubles $(15.2 \%$ to $28.7 \%$ ) as sodium valproate concentration is raised from zero to $882 \mu \mathrm{mol} / 1$.

That the observed \% bound DPH in normal plasma $(77.5 \%)$ was increased when defatted plasma was used $(84.8 \%)$ suggests that naturally occurring free fatty acids affect the degree of binding by DPH to its binding sites. Furthermore, the trend and indeed the scatter of the results in the untreated human and rat plasma would be in line with this. By contrast the negative data presented in Table $3 \mathrm{~b}$ with ethosuximide, which is known to be weakly bound to plasma protein and does not compete for DPH binding sites (Lunde et al., 1970; Hooper et al., 1973), are compatible with the concept that the change observed in the presence of sodium valproate is due to displacement effects.

The displacement of DPH from plasma protein binding sites in patients on drug treatment with DPH and sodium valproate in the chronic situation might be expected to have the effect of lowering very slightly 
the total DPH plasma concentration (as observed in our rats), and indeed a carefully controlled clinical study by Vakil et al. (1976) has indicated that this is the case.

The practical significance of these observations is that sodium valproate added to the therapeutic regime of a patient already on DPH, which itself has had to be taken to the upper limit of the accepted therapeutic range, may well precipitate features of DPH intoxication which would not be predicted from an estimation of the plasma total DPH concentration.

We wish to thank Reckitt and Colman Ltd for free samples of sodium valproate and for financial and technical assistance. We also wish to thank Mr J. Hughes for assistance in the animal work.

\section{References}

Chen, R. F. (1967). Removal of free fatty acids from serum albumin by charcoal treatment. Journal of Biological Chemistry, 242, 173-181.

Hansen, J. M., Kristensen, M., and Skovsted, L. (1968). Sulthiame (Ospolot) as inhibitor of diphenylhydantoin metabolism. Epilepsia, 9, 17-22.

Hooper, W. D., Sutherland, J. M., Bochner, F., Tyrer, J. H., and Eadie, M. J. (1973). The effect of certain drugs on the plasma protein binding of diphenylhydantoin. Australian and New Zealand Journal of Medicine, 3, 377-381.

Houghton, G. W. and Richens, A. (1974). Inhibition of phenytoin metabolism by sulthiame in epileptic patients. British Journal of Clinical Pharmacology, 1, 59-66.

Jeavons, P. M. and Clark, J. E. (1974). Sodium valproate in treatment of epilepsy. British Medical Journal, 2, 584-586.

Jordan, B. J., Shillingford, J. S., and Steed, K. P. (1975). Preliminary observations on the protein binding and enzyme inducing properties of sodium valproate (Epilim). In Clinical and Pharmacological Aspects of Sodium Valproate (Epilim) in the Treatment of Epilepsy.
Proceedings of a Symposium, Nottingham University, September 1975. MCS Consultants: Tunbridge Wells.

Klotz, I. M., Walker, F. M., and Pivan, R. B. (1946). Binding of organic ions by proteins. Journal of the American Chemical Society, 68, 1486-1490.

Lunde, P. W. M., Rane, A., Yaffe, S. J., Lund, L., and Sjöquist, F. (1970). Plasma protein binding of diphenylhydantoin in man. Interaction with other drugs and the effect of temperature and plasma dilution. Clinical Pharmacology and Therapeutics, II, 846-855.

Meinardi, H. (1971). Clinical trials of antiepileptic drugs. Psychiatria. Neurologia, Neurochirurgia, 74, 141-151.

Patsalos, P. N. and Lascelles, P. T. (1976). The effect of various anticonvulsants on the in vitro hydroxylation of diphenylhydantoin. In press.

Patsalos, P. N., Goldberg, V. D., and Lascelles, P. T. (1975). Determination of sodium valproate and sulthiame in plasma by gas liquid chromatography and the study of their interaction with diphenylhydantoin. Proceedings of the Analytical Division of the Chemical Society, 12, 270-271.

Suzuki, M., Maruyama, H., Ishibashi, Y., Ogawa, S., Seki, T., Hoshino, M., Maekawa, K., Yo, T., and Sato, Y. (1972). A double blind comparative trial of sodium diprolacetate and ethosuximide in epilepsy in children, with special emphasis on pure and petit mal seizures. Medical Progress, 82, 470-488.

Toseland, P. A., Grove, J., and Berry, D. J. (1972). An isothermal G.L.C. determination of the plasma levels of carbamazepine, diphenylhydantoin, phenobarbitone and primidone. Clinica Chimica Acta, 38, 321-328.

Tsutsumi, E., Inaba, T., Mahon, W. A., and Kalow, W. (1974). The displacement effect of a fatty acid on the binding of diazepam to human serum albumin. Biochemical Pharmacology, 24, 1361-1362.

Vakil, S. D., Critchley, E. M. R., Philips, J. C., Haydock, C., Cocks, A., and Dyer, T. (1976). The effect of sodium valproate (Epilim) on phenytoin and phenobarbitone blood levels. In Clinical and Pharmacological Aspects of Sodium Valproate (Epilim) in the Treatment of Epilepsy. Proceedings of a Symposium, Nottingham University, September 1975. MCS Consultants: Tunbridge Wells. 